\title{
Characteristics and Complications of Tuberculous Meningitis Patients with Hydrochepalus Undergone Fluid Diversion in Dr. Hasan Sadikin General Hospital, Bandung
}

\author{
Adriani Lawrencia Novalia, ${ }^{1}$ Afiat Berbudi, ${ }^{2}$ Ahmad Faried, ${ }^{3}$ Heda Melinda Nataprawira ${ }^{4}$ \\ ${ }^{1}$ Faculty of Medicine, Universitas Padjadjaran \\ ${ }^{2}$ Department of Microbiology and Parasitology, Faculty of Medicine, Universitas Padjadjaran \\ ${ }^{3}$ Department of Neurosurgery, Faculty of Medicine Universitas Padjadjaran-Dr. Hasan Sadikin General Hospital, \\ Bandung \\ ${ }^{4}$ Department of Child Health, Faculty of Medicine, Universitas Padjadjaran-Dr. Hasan Sadikin General Hospital, \\ Bandung
}

\begin{abstract}
Objective: To describe the clinical characteristics and complications observed in tuberculous meningitis (TBM) patients with hydrocephalus who had undergone fluid diversion management.

Methods: This was a cross-sectional descriptive observational study involving 28 TBM patients with hydrocephalus aged $0-5$ years who had undergone ventriculoperitoneal shunt or extraventricular drainage in the period of July 2011 to July 2016 in Dr. Hasan Sadikin General Hospital, Bandung. Age, gender, head circumferences, nutritional status, and classical characteristics such as sunset eye, frontal bossing, cracked pot sign, venectation as well as complications such as infection, phlebitis, and exposed shunt documented in the hospital medical records were analyzed.

Results: The study discovered that infant group was predominant $(21 / 28)$. Some of the patients had macrocephalus $(7 / 28)$ and 18 had good nutrition status $(18 / 28)$. There were 4 patients with frontal bossing characteristics (4/28) and almost none was found with others classic hydrocephalus characteristics. This study found no complication such as infection, phlebitis, and exposed shunt in TBM patients with hydrocephalus who had undergone fluid diversion therapy in Dr. Hasan Sadikin General Hospital, Bandung.

Received:

July 10, 2017

Revised:

Conclusions: One of the most dominan characteristics of TBM patients with hydrocephalus is frontal bossing. Tuberculous meningitis patients with hydrocephalus in our center did not show any fluid diversion-related complications such as infection, phlebitis, or exposed shunt.
\end{abstract}

October 26, 2017

Accepted:

February 19, 2018
Keywords: Tuberculous meningitis, hydrocephalus, fluid diversion

pISSN: 2302-1381; eISSN: 2338-4506; http://doi.org/10.15850/ijihs.v6n1.1048 IJIHS. 2018;6(1):6-10

\section{Introduction}

Tuberculous meningitis, or commonly known as TBM, is inflamation of the brain meningenlayer caused by Mycobacterium tuberculosis. ${ }^{1}$ Tuberculous meningitis is regarded as one of extrapulmonarytuberculosis(TB) diseases. The World Health Organization or WHO has shown

Correspondence:

Adriani Lawrencia Novalia, Faculty of Medicine, Universitas Padjadjaran

Jl. Raya Bandung-Sumedang KM 21 Jatinangor,

Indonesia

e-mail: adrianilawrencianovalia@gmail.com that there is a high number of extrapulmonary TB cases in Indonesia. In 2014, 19.653 cases was found in Indonesia. ${ }^{2}$ Tuberculous meningitis often leads to hydrocephalus as its complication. Multiplication of Mycobacterium $T B$ establishes a rich focus in meningen-tissue or brain parenchyma which will increase the responses from T-cell, tumor necrosis factor-alpha (TNF- $\alpha$ ), and interferon-gamma (IFN- $\gamma$ ), causing the necrosis of the rich focus leading to spreading of the bacteria into subarachnoid space via the blood brain barrier. This will stimulate the secretion of cytokine, TNF- $\alpha$, and other inflammation 
factors, triggering the formation of exudate in the subarachnoid space. This exudate contains erythrocytes, neutrophils, macrophages, and lymphocytes and will condense and adhere to villi arachnoid, impairing cerebrospinal fluid absorption. This will then followed by the accumulation of cerebrospinal fluid in brain ventricle, causing it to dilate and eventually leads to hydrocephalus. ${ }^{3,4}$ The hydrocephalus in TBM is classified into the communicating obstructive hydrocephalus. The classic clinical presentations of hydrocephalus are increased head circumference, frontal bossing, sunset eye phenomenon, cracked pot sign, venectation, and neurological impairment. ${ }^{5}$

Treatments for cerebrospinal accumulation in brain include ventriculoperitoneal shunt (VP shunt) and external ventricular drain (EVD) that are intended for draining excess fluid from the ventricular system into a part of the body that has a better ability to absorb. However, a former study has shown that VP shunt or EVD therapy causes many complications including infection, shunt obstruction, peritonitis, and slit-ventricular syndrome. ${ }^{6}$ However, the data from this previous study came from cases of hydrocephalus complication that is not caused by TBM.

Hence, it is necessary to perform a study on clinical characteristics and complications of TBM with hydrocephalus after fluid diversion therapy. The aim of this study was to describe the clinical characteristics and complications of TBM with hydrocephalus after receiving fluid diversion therapy. The result could be used as scientific data for better management.

\section{Methods}

This study was a cross-sectional descriptive observational study targeted to all patients registered at the Department of Neurosurgery, Dr. Hasan Sadikin General Hospital, Bandung who were diagnosed as suffered from TBM with hydrocephalus, aged $0-5$ years old, during July 2011 until July 2016. Tuberculous meningitis and hydrocephalus patients with HIV, cerebral palsy history, congenital anomaly, spinal cord injury, spondylitis TB, and those who did not undergo VP shunt or EVD were excluded from this study. Data collected in this study were age, sex, nutritional status, head's circumference, and hydrocephalus clinical characteristics that include frontal bossing, sunset eye, cracked pot sign and venectation. Nutritional status and head circumference were determined using the WHO growth charts.
Complications found in the hydrochepalic TBM patients such as infection, phlebitis, or exposed shunt were observed two weeks after fluid diversion therapy. Medical records of the patients were used to look for complications after fluid diversion from patients receiving VP shunt and EVD at our center in Dr. Hasan Sadikin Hospital, Bandung. The patients with incomplete or missing medical records were excluded. Analysis was performed by using computerizad software. This study was approved by the Research Ethics Committee of Dr. Hasan Sadikin General Hospital, Bandung and all medical records are kept confidential and protected.

\section{Results}

Seventy nine patients, 0-5 years old, with TBM and hydrocephalus with no congenital abnormality and HIV infection were identified. Of these patients, only 39 patients received fluid diversion therapy with only 28 patients had complete information recorded in their medical records.

Most common age group from all 28 TBM with hydrocephalus patients receiving fluid diversion therapy was infancy (0-1 year old) age group (21 patients) followed by toddler (3-5 years old) and preschool( 4 patients) age groups. In sex characteristics, there was no domination. Sex ratio of TBM patients with hydrocephalus who received fluid diversion therapy was 1:1 (Table 1). The majority of patients had normal head circumference (17 patients), followed by macrocephalus group and microcephalus group (Table 2).

All patients with macrocephalus were those aged 0-24 months old or was in the infant category and open anterior fontanel.

\section{Table 1 Characteristics of Tuberculosis Menginitis with Hydrocephalus Patient by Age and Gender}

\begin{tabular}{lc}
\hline \multicolumn{1}{c}{ Characteristics } & Total \\
\hline Age (yrs.) & \\
Infancy (0-1) & 21 \\
Toddlerhood (2-3) & 3 \\
Preschool (3-5) & 4 \\
Gender & \\
Male & 11 \\
Female & 14 \\
\hline
\end{tabular}

Note: yrs. $=$ years 
Characteristics and Complications in Tuberculous Meningitis Hydrocephalus Patient Undergone Fluid Diversion in Department Of Neurosurgery, Dr. Hasan Sadikin General Hospital, Bandung

\begin{tabular}{|c|c|}
\hline Characteristic & Total \\
\hline \multicolumn{2}{|l|}{ Head circumference } \\
\hline Normal & 17 \\
\hline Macrocephalus & 7 \\
\hline Microcephalus & 3 \\
\hline \multicolumn{2}{|l|}{ Nutritional status } \\
\hline Obesity & 1 \\
\hline Good nutrition & 18 \\
\hline Malnutrition & 2 \\
\hline Severe malnutrition & 7 \\
\hline
\end{tabular}

From the body weight and height, it was identified that 18 TBM with hydrocephalus patients receiving the fluid diversion therapy had good nutritional status. Approximately 7 were severely malnourished, another 7 were malnourished, and only one was obese (Table 2).

From the data fround regarding the classic characteristics of TBM-related hydrocephalus, ifrontal bossing was found to be the most common characteristic (4), followed by the presence of venectation (2), and sunset eye (1). Based on data, there was no cracked pot sign found in all 28 sampled patients (Table 3 ). However, the incidence of frontal bossing in TBM with hydrocephalus patients receiving fluid diversion therapy was still too diminutive.

From 28 TBM patients with hydrocephalus receiving fluid diversion therapy, none of them had experienced infection, phlebitis, or exposed shunt during two weeks after fluid diversion therapy (Table 4). However, based on the data, there were two patients experiencing proximal shunt malfunction.

Table 3 Classic Characteristics of Tuberculosis Menginitis with Hydrocephalus

\begin{tabular}{lcc}
\hline \multicolumn{1}{c}{ Characteristic } & Yes & No \\
\hline Sunset Eye & 1 & 27 \\
Frontal Bossing & 4 & 24 \\
Cracked pot Sign & 0 & 28 \\
Venectation & 2 & 26 \\
\hline
\end{tabular}

Table 4 Complication on Tuberculous Menginitis with Hydrocephalus Patients with VP Shunt Treatment

\begin{tabular}{lcc}
\hline \multicolumn{1}{c}{ Characteristic } & Yes & No \\
\hline Infection & 0 & 28 \\
Phlebitis & 0 & 28 \\
Exposed Shunt & 0 & 28 \\
\hline
\end{tabular}

\section{Discussion}

Tuberculous meningitis with hydrocephalus is an inflammation of brain meninges caused by Mycobacterium TB accompanied by dilatation of all brain ventricle systems. Hydrocephalus is formed in $42 \%$ of TBM patients. ${ }^{7,8}$

In a former study, the average age of TBM patients is 4 months to 18 years old..$^{9}$ In this study, 21 subjects were from infant $(0-1$ year old) age group. This is an agreement with a previous study performed by Tung et al. ${ }^{10}$ with an average of patients of 7.6 months old with an age span of 5-11 months old. The high numbers of TBM in infancy is because infants are more susceptible to infection due to their immature immune system, which allows $T B$ Mycobacterium multiplication and increasing disease progressivity. ${ }^{4}$

A previous study also discovered that boys have a higher tendency to have TBM, both in children or adults. ${ }^{8,9}$ However, those studies are limited to TBM only without considering the presence of hydrocephalus. It was found that TBM patients with hydrocephalus in the age group of $0-5$ years old does not show a sex presentation difference

One of the characteristics of hydrocephalus is increasing head circumference. A previous study, head circumference correlates with the brain volume and is very much affected by age; hence, head circumference measurement by age can be used to determine the presence of brain volume abnormality.11 Result of this study showed that seven patients had macrocephaly. Patients with macrocephaly are within 0-24 months old with open anterior fontanel. This matches the theory stated that 93\% baby's fontanel are closed at 24 months old. ${ }^{12}$ Head circumference enlargement rate may increase because of accumulation of fluid in ventricle and subarachnoid space, leading to dilatation of membrane connecting cranial bones.

In addition to increased head circumference, another thing that may occur in hydrocephalus 
patients with open anterior fontanel is frontal bossing. ${ }^{12}$ In this study, frontal bossing was found in up to $17 \%$ of the patients. All of them are in infancy category. This was caused by the fact that open anterior fontanel allows the accumulated fluid in ventricular system to press the intracranial components, leading to the enlargement anterior parts. Enlargement of head circumference and the presence of frontal bossing leads to upper retraction of the eyelids and the accumulation of cerebrospinal fluid press brain component creates increased intracranial pressure and repression of cranial nerves, causing the sunset eye phenomenon or the condition in which the eyelids are retracted above and the eyeball is deviated downward, creating a sunset-like look. ${ }^{13}$ In this study, sunset eye phenomenon was seen in patients with frontal bossing.

The increased intracranial pressure will repress the cranial nerve and giving symptoms like oculomotor palsy. It will be happened if the third cranial nerve is stretched due to intracranial pressure. Repression of the sixth cranial nerve leads to diplopia. ${ }^{7}$ Hydrocephalus patients who experience severe enlargement of head circumference as well as severe frontal bossing will be seen with venectation and cracked pot sign (sign of percussion sound like a cracking pot). However, in this study there is no cracked pot sign found. This is influenced by the growth progressivity of TB bacteria that adher to arachnoid villi that leads to cerebrospinal fluid malabsorption. With time, without therapy, hydrocephalus complication increases. Theoretically, cerebrospinal fluid is absorbed via the arachnoid villi and Virchowrobin spaces (VRS).

Cerebrospinal fluid absorption via VRS may happen during an increase in hydrostatic pressure in the arteriole, pushing fluid into VRS, causing the fluid to flows into ventricle and enter the lymphatic system, back to blood vessels. ${ }^{14}$ This explains the ability of the early treatmentfor TBM patients with hydrocephalus to diminish the all four characteristics.
Patients who are suffering from tuberculous meningitis with hydrocephalus receive not only anti-TB therapy to eradicate the bacteria, but also fluid diversion therapy to relieve the hydrochepalus. Based on existing literatures, 36 infection cases following VP shunt and 46 shunt cases were found. ${ }^{15} \mathrm{~A}$ previous study showed that about 58\% shunt infection are caused by gram negative bacilli bacteria, followed by $S$. aureus, $S$. epidermidis, and Staphylococcus haemolyticus. ${ }^{16}$ Another study has reported exposed shunt at perioral area in 1 year old children. ${ }^{17}$

Based on medical record analysis, it was found that all samples do not present any information of the presence of infection, phlebitis, or exposed shunt after VP shunt or EVD procedure. However, this result needs further investigation, since patients data are taken in only in one center and only focusing in patients receiving fluid diversion at the Department of Neurosurgery, Dr. Hasan Sadikin Hospital, Bandung; therefore, it cannot be said that patient with fluid diversion will have no complication. Multicenter collaboration and data collections are needed in the near future.

The limitation in this study is in the small sample size due to the difficulties in finding good and complete medical records. Further studies about the clinical characteristics of TBM with hydrocephalus involving other centers are needed. In spite of the limitation, the results can be used as a reference to provide an explanation of the patient's condition and the complications that occur after fluid diversion therapy.

Hence, characteristics such as enlargement of head circumference and frontal bossing are influenced by the patient's age because the fontanel closure influences the characteristics of hydrocephalic TBM patients. Complications that are usually seen after fluid diversion are not found in this study. It can be assumed then that fluid diversion therapy at the Department of Neurosurgery, Dr. Hasan Sadikin Hospital, has fulfilled the infection prevention standards.

\section{References}

1. Kasper D. Harrison's principles of internal medicine, $19^{\text {th }}$ ed. New York: Mcgraw-hill; 2015.

2. World Health Organization. Global tuberculosis report 2015, Geneva: World Health Organization; 2015.

3. Rock RB, Olin M, Baker CA, Molitor TW,
Peterson PK. Central nervous system tuberculosis: Pathogenesis and clinical aspects. Clin Microbiol Rev. 2008;21(2):243-61.

4. Newton SM, Brent AJ, Anderson S, Whittaker E, Kampmann B. Paediatric tuberculosis. Lancet Infect Dis. 2008;8(8):498-510. 
5. Wu T, Li HQ. Changes of anterior fontanel size in children aged 0-2 years. Zhonghua Er Ke Za Zhi. 2012;50(7):493-7.

6. Athanasakis E, Ermidou D. Post-operative complications of ventriculoperitoneal shunt in hydrocephalic pediatric patients-nursing care. Int J Caring Sci. 2011;4(2):66-71.

7. Anderson NE, Somaratne J, Mason DF, Holland D, Thomas MG. Neurological and systemic complications of tuberculous meningitis and its treatment at Auckland City Hospital, New Zealand. J Clin Neurosci. 2010;17(9):1114-8.

8. Güneş A, Uluca Ü, Aktar F, Konca Ç, Şen V, Ece $A$, et al. Clinical, radiological and laboratory findings in 185 children with tuberculous meningitis at a single centre and relationship with the stage of the disease. Italian J Pediatr. [serial on the internet]. 2015 Oct [cited 2016 Mar 20];41:(75):[about 6p.]. Available from: https://www.ncbi.nlm.nih.gov/pmc/articles/ PMC4606503/.

9. Miftode EG, Dorneanu OS, Leca DA, Juganariu G, Teodor A, Hurmuzache M, et al. Tuberculous meningitis in children and adults: a 10-year retrospective comparative analysis. PLOS ONE. [serial on the internet]. 2015 Jul [cited 2016 Mar 20];10(7):[about 10p.]. Available from: http://journals.plos.org/plosone/ article?id=10.1371/journal.pone.0133477.

10. Tung YR, Lai MC, Lui CC, Tsai KL, Huang LT, Chang YC, et al. Tuberculous meningitis in infancy. Pediatr Neurol. 2002;27(4):262-6.

11. Treit S, Zhou D, Chudley AE, Andrew G, Rasmussen C, Nikkel SM, et al. Relationships between head circumference, brain volume and cognition in children with prenatal alcohol exposure. PLOS ONE. [serial on the internet]. 2016 Feb [cited 2016 Jul 27];11(2):[about 15p.]. Available from: http://journals.plos. org/plosone/article?id=10.1371/journal. pone.0150370.

12. Kiesler J, Ricer R. The abnormal fontanel. Am Family Phys. 2003;67(12):2547-52.

13. Boragina $M$, Cohen $E$. An infant with setting-sun eye phenomenon. CMAJ. 2006;175(8):878-9.

14. Brinker T, Stopa E, Morrison J, Klinge P. A new look at cerebrospinal fluid circulation. Fluids and Barriers of the CNS. [serial on the internet]. 2014 May [cited 2016 Jul 27];11(10):[about 16p.]. Available from: https://fluidsbarrierscns.biomedcentral.com/ articles/10.1186/2045-8118-11-10.

15. Park M-K, Kim M, Park K-S, Park S-H, Hwang $\mathrm{J}-\mathrm{H}$, Hwang SK. A retrospective analysis of ventriculoperitoneal shunt revision cases of a single institute. J Korean Neurosurg Soc. 2015;57(5):359-63.

16. Wu X, Liu Q Jiang $X$, Zhang T. Prevention options for ventriculoperitoneal shunt infections: a retrospective analysis during a five-year period. Int J Clin Experimental Med. 2015;8(10):19775-80.

17. Agarwal M, Adhana $R$, Namdev $H$, Yadav YR, Agrawal T. Transoral extrusion of the ventriculo-peritoneal shunt: a case report and review of literature. J Pediatr Neurosci. 2011;6(2):149-51. 